Article

\title{
Advanced Methodologies for Biomass Supply Chain Planning
}

\author{
Duy Nguyen Duc and Narameth Nananukul * \\ School of Management Technology, Sirindhorn International Institute of Technology, Thammasat University, \\ Pathum Thani 12120, Thailand \\ * Correspondence: narameth@siit.tu.ac.th
}

Received: 26 August 2019; Accepted: 25 September 2019; Published: 26 September 2019

check for updates

\begin{abstract}
Renewable energy resources have received increasing attention due to environmental concerns. Biomass, one of the most important renewable energy resources, is abundant in agricultural-based countries. Typically, the biomass supply chain is large due to the huge amount of relevant data required for building the model. As a result, using a standard optimization package to determine the solution for the biomass supply chain model might not be practical. In this study, the focus is on developing and applying advanced methodologies that can be used to determine a solution for the biomass supply chain model efficiently. The decisions related to plant selection, and distribution of biomass from suppliers to plants require optimization. The methodologies considered in this research are based on stochastic programming, parameter search, and simulation-based optimization. Computational results and managerial insights based on case studies from different regions of Vietnam are provided. The results show that parameter search is suitable for small problems only, while stochastic programming is suitable for small and medium problems. For large problem, simulation-based optimization performs better when considering the quality of the solution and the run time, although, this method does not guarantee an optimal solution. It provides good solutions where the gaps to the optimal solutions are between $0.59 \%$ and $8.41 \%$.
\end{abstract}

Keywords: hybrid methodology; simulation-based optimization; parameter search optimization; biomass supply chain planning; stochastic programming

\section{Introduction}

Nowadays, there has been a significant increase in energy generation from renewable energy resources in many countries. Therefore, supply chain planning for renewable energy production and distribution has become an important task in order to achieve high operational efficiency [1]. There are many forms of energy that can be generated, but electricity is the most common due to its ability to be distributed over high-voltage power lines. Biomass is an available renewable energy resource and is abundant in most countries that rely on agricultural industry.

In general, the biomass supply chain planning problem is very large and complicated due to the amount of data that needs to be considered and the interactions among different components within the supply chain [2]. For example, when the numbers of suppliers and factory candidate locations are increased, decisions related to the amount of biomass to be ordered from suppliers and facilities are more complex. Besides, in the typical biomass supply chain, there exists uncertainty from factors such as supply capacity and electricity demand, which fluctuates over the years. The design of biomass supply chains for alternative energy sources has caught the attention of many researchers. For example, Cambero et al. [3] and Liu et al. [4] designed biomass supply chains utilizing forest residue as an energy source. Jonker et al. [5] focused on the design of a supply chain for ethanol production in Brazil. 
Vietnam, an Asian country located in the tropics, is abundant with agricultural products. As a result, it has high potential for the use of biomass for electricity generation. Traditionally, biomass has been the major source of energy for rural households. Based on a report from the Asian Development Bank [6], electricity consumption (per capita) increased from 156 kilowatt-hours (kWh) in 1995 to $983 \mathrm{kWh}$ in 2010 and $1415 \mathrm{kWh}$ in 2014. Electricity demand during 2016-2020 is expected to grow an average of $10.5 \%$ per annum, and $8.0 \%$ per annum during 2021-2030. In order to ensure national energy security, the national energy development strategy in Vietnam has focused on promoting the use of renewable energy sources, including the ability to manage energy resources effectively and sustainably while considering environmental protection [7]. This is similar to the adopted energy policy by the Chinese government [8]. As a result, the ability to use biomass effectively as an alternative energy source is a major attempt to support the national energy policy.

In this study, a supply chain planning model for determining the optimal biomass plant locations is introduced. The objective is to maximize the benefits by simultaneously considering transportation cost, purchasing cost, opening fixed cost, inventory cost, penalty cost for lost demand, and uncertainty from factors such as supply capacity and electricity demand. The biomass plants considered in this research are installed with appropriate waste treatment systems such as an electrostatic precipitator (ESP), which has collection efficiency above 90\% [9], and as a result the emissions from the plants will not violate environmental regulations. This can be compared with energy generation from coal-fired power plant, where more than $70 \%$ of existing coal-fired power plants that meet environmental regulations have installed ESP system [10]. The energy conversion system installed at the biomass plant is assumed to be cost effective, and environmentally friendly [11]. Furthermore, due to the complexity of the proposed model, advanced methodologies based on stochastic optimization, parameter search, and simulation-based optimization are proposed for solving the large-scale biomass supply chain problem in order to compare the performance of the methods. This is considered an innovative point of this research because this is an area that very few researchers have focused on.

Optimization is a scientific approach to achieve expected performance, such as minimizing the expected cost or maximizing the expected profit [12]. Optimization-based methods tend to take a longer time to solve the problem and sometimes fail to provide a solution due to the required computational load $[2,13,14]$. This complexity has motivated the development of simulation tools that can be used to analyze and evaluate the dynamic behavior of complex systems [2,15]. However, the functional relationship between components in a simulation model is complicated and not easy to coordinate, and as a result, a combination of optimization and simulation methods, the hybrid simulation-based optimization (hybrid) method, was developed. The hybrid method has the advantages of simulation and optimization methods and the ability to solve large-scale problems within practical computation time.

In this study, three methodologies for determining a solution for the biomass supply chain problem are considered. The first is based on a stochastic optimization model. The proposed model is extended from Duc and Nananukul [16], where uncertainty from supplier capacity is considered. The second is based on a solution methodology from a simulation method called parameter optimization, which is used for optimizing a set of parameters used in the simulation model. The third is based on simulation-based optimization, which integrates simulation with optimization. The simulation model for biomass supply chain planning was developed by using a simulation model from Matlab Simulink. The efficiency of the biomass supply chain system is improved by changing the values of certain parameters of the simulation model. This function was implemented by using a built-in function of Matlab Simulink called parameter-setting in order to optimize the values of parameters.

In the hybrid model, an optimization model was formulated and integrated with the simulation model. The optimization model was formulated as a mixed-integer programming model, which was integrated with the Matlab Simulink model. Uncertainty from demand and supplier capacity is considered in the model, and the values of demand and supplier capacity are generated from the simulation model and used as input to the optimization model. The optimization model defines core parameters and decision variables for the simulation model in each period, in which an interactive 
process enables the hybrid model to automatically consider whole periods [17]. Data from different regions of Vietnam were used to determine the optimal biomass plant locations.

The rest of this paper is organized as follows: Section 2 presents a literature review on stochastic programming, simulation and parameter optimization, and simulation-based optimization in supply chain management. Section 3 presents the stochastic, simulation, and hybrid models. Section 4 provides case studies to illustrate the methodologies, with a discussion of the results. Finally, the conclusion and future work are summarized in Section 5.

\section{Literature Review}

In this section, the literature review is summarized in four categories.

\subsection{Stochastic Model for Supply Chain Management}

Ekşioğlu et.al. [13] conducted a logistics analysis of supplying biomass to a biorefinery. A mathematical model was used to design the supply chain and manage the logistics. Then, long-term and short-term decisions were analyzed based on the generated scenarios. Cambero et al. [3] considered a multiperiod mixed-integer linear programming model to determine the location, type of technology, and size of the facility to be installed in a forest residue supply chain. Wu et al. [18] developed a nonlinear mixed-integer programming model to determine the location and allocation solution while considering construction, transportation, and labor costs. Liu et al. [4] investigated the utilization of forest biomass to generate electricity at a second-generation bioethanol coproduction plant. The model considers the price of electricity, heating value, and raw material cost to determine the most vital parameter. Gonela [19] addressed a hybrid electricity supply chain (HESC) that utilized coal and biomass for electricity generation in North Dakota, USA. The author aimed to design a sustainable electricity system under uncertainty from coal mining, biomass yield, and electricity conversion rates. Sarker et al. [20] introduced a biogas supply chain that included hubs, reactors, condensers, and demand points. A genetic algorithm was developed and used to solve a mixed-integer nonlinear model to locate hubs, reactors, and condensers in order to minimize total cost.

\subsection{Simulation Model for Supply Chain Management}

Papapostolou et al. [21] developed a simulation model for a biofuel supply chain. By using delivered feedstock cost, energy consumption, and greenhouse gas emissions as performance criteria, the model can be used to select optimal biofuel facility locations in a biofuel supply chain. Wang et al. [22] investigated a simulation model for a corn stover logistics system in southwestern Ontario, Canada. The authors analyzed the impact of the biorefinery size on the required biomass resources. Sharma et al. [23] developed a discrete event simulation model for a supply chain to evaluate the impact of operational disruptions on supply chain cost, inventory, and production level. A simulation model was used to perform the analysis based on different scenarios. Vieira et al. [24] presented an integrated framework consisting of a simulation model and big data to analyze the impact of risk scenarios in an automotive supply chain. Data from multiple sources were collected and stored in a big data warehouse, then analyzed and used by a simulation model. Akhtari et al. [25] analyzed the impact of two inventory systems, order up to level and fixed order quantity, in a forest-based biomass supply chain in Canada. Cost, demand fulfilment, and $\mathrm{CO}_{2}$ emissions were used as key performance indicators.

\subsection{Simulation-Based Optimization in Supply Chain Management}

Due to its simplicity, simulation-based optimization has been applied to many operational decision-making processes. A literature review related to simulation-based optimization methodology is summarized as follows:

Nikolopoulou and Ierapetritou [2] considered a large-scale mixed-integer linear problem in supply chain management that minimized total cost, consisting of production cost, transportation cost, 
inventory holding, and shortage costs. The approach provided a reasonable solution with relatively few iterations and low computation time. Bjelić and Rajaković [1] looked at a smart electricity grid that considered an optimal mix of supply and demand sides with technical measures that include energy efficiency, renewable energy, and structural measures. In the hybrid framework, decision vectors were chosen and explained based on the optimization of scenarios created in the simulation. Chu et al. [26] addressed inventory systems with two case studies in Serbia. An agent-based system, which returns the performance functions, was simulated and estimated by the Monte Carlo method. Then, the optimization problem was solved by a cutting plane algorithm. A local optimal solution was achieved after testing optimality conditions.

Chávez et al. [27] proposed a simulation-based optimization approach for a transportation problem with highly unpredictable characteristics. The results from a stochastic multiobjective minimum cost flow model demonstrated the effectiveness of the simulation-based multiobjective optimization. Real data from the transportation of agricultural products from Mexico to the United States were used as a case study. Ye and You [28] considered an inventory problem with demand uncertainty from sales regions, delivery preparation time, and production time. The optimal base-stock levels for the entire system were determined to minimize total cost, including inventory holding cost and back-ordering cost. Ge et al. [29] considered an agricultural supply chain with various characteristics in Canada. The objective was to maintain food safety and effectively manage the operation cost in a wheat supply chain by developing a set of contamination testing strategies.

Dengiz and Belgin [15] summarized the benefits of a hybrid simulation-analytical optimization approach when considering a case study in a paint shop production system. The proposed approach was used to identify the values of critical variables, and the simulation was used to analyze system behavior. Tsai and Chen [30] considered a multiobjective inventory problem where reorder point and order quantity were key variables. The authors also proposed new algorithms to provide statistically valid ranking and selection for a multiobjective optimization problem. Then, the efficiency was evaluated by a simulation approach. Avci and Selim [31] considered an inventory replenishment problem with premium freights in a convergent supply chain.

\subsection{Parameter Optimization Methodology in Supply Chain Management}

There are several relevant streams of literature on parameter optimization methodology. Kelle et al. [32] focused on inventory management at a local storage unit of a pharmaceutical supply chain. The reorder point and order up to level were considered as parameters and determined based on a near-optimal allocation policy of cycle stock and safety stock under storage space constraints. Tsai and Zheng [33] considered an algorithm for the constrained multi-echelon inventory problem. A reasonable sequence of parameter settings for ranking and selection was discussed as part of a simulation-based optimization approach to define the optimal setting of stock levels. The approach provided near-optimal solutions that were better than the results from other algorithms with less computational effort.

Fischer et al. [34] proposed the use of genetic algorithm and particle swarm optimization for robust optimization of the flexible parameters in a production process. Kaminsky and Liu [35] considered parameter optimization based on stochastic gradient estimation, retrospective optimization, and neighborhood search. Retrospective optimization was applied for parameter setting based on the results of an earlier work. Then, a combination of retrospective optimization and gradient search algorithm was applied to an inventory problem of a biopharmaceutical supply chain. Kush et al. [36] investigated a model for parameter optimization of a freight transportation process. The total logistics cost, consisting of transportation and storage costs, was used as an effectiveness measurement.

A summary of the methods used in key related articles is shown in Table 1. 
Table 1. A summary of the methods used in key related articles.

\begin{tabular}{|c|c|c|c|c|c|c|c|}
\hline No. & Authors & Year & 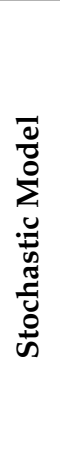 & 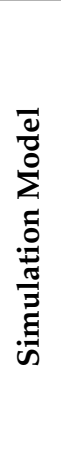 & 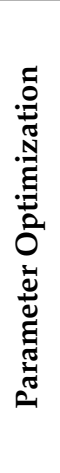 & 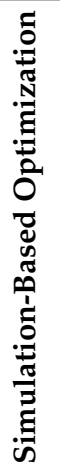 & 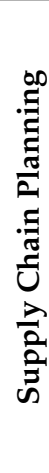 \\
\hline 1 & Ekşioğlu et al. [13] & 2009 & $x$ & & & & $x$ \\
\hline 2 & Wu et al. [18] & 2015 & $x$ & & & & $\mathrm{x}$ \\
\hline 3 & Cambero et al. [3] & 2015 & $x$ & & & & $x$ \\
\hline 4 & Liu et al. [4] & 2017 & $x$ & & & & $x$ \\
\hline 5 & Gonela [19] & 2018 & $\mathrm{x}$ & & & & $\mathrm{x}$ \\
\hline 6 & Sarker et al. [20] & 2019 & $x$ & & & & $x$ \\
\hline 7 & Papapostolou et al. [21] & 2011 & & $x$ & & & $x$ \\
\hline 8 & Wang et al. [22] & 2017 & & $x$ & & & $x$ \\
\hline 9 & Sharma et al. [23] & 2018 & & $x$ & & & $x$ \\
\hline 10 & Akhtari et al. [25] & 2019 & & $\mathrm{x}$ & & & $\mathrm{x}$ \\
\hline 11 & Vieira et al. [24] & 2019 & & $x$ & & & $x$ \\
\hline 12 & Nikolopoulou and Ierapetritou [2] & 2012 & & & & $\mathrm{x}$ & $x$ \\
\hline 13 & Bjelić and Rajaković [1] & 2015 & & & & $x$ & $x$ \\
\hline 14 & Chu et al. [26] & 2015 & & & & $x$ & $\mathrm{x}$ \\
\hline 15 & Chávez et al. [27] & 2015 & & & & $\mathrm{x}$ & $\mathrm{x}$ \\
\hline 16 & Ye and You [28] & 2016 & & & & $x$ & $\mathrm{x}$ \\
\hline 17 & Ge et al. [29] & 2016 & & & & $\mathrm{x}$ & $\mathrm{x}$ \\
\hline 18 & Dengiz and Belgin [15] & 2016 & & & & $x$ & $x$ \\
\hline 19 & Tsai and Chen [30] & 2017 & & & & $x$ & $\mathrm{x}$ \\
\hline 20 & Avci and Selim [31] & 2018 & & & & $\mathrm{x}$ & $\mathrm{x}$ \\
\hline 21 & Kelle et al. [32] & 2012 & & $\mathrm{x}$ & $x$ & & $x$ \\
\hline 22 & Tsai and Zheng [33] & 2013 & & $\mathrm{x}$ & $x$ & & $\mathrm{x}$ \\
\hline 23 & Fischer et al. [34] & 2014 & & $x$ & $x$ & & $x$ \\
\hline 24 & Kaminsky and Liu [35] & 2018 & & $\mathrm{x}$ & $\mathrm{x}$ & & $x$ \\
\hline 25 & Kush et al. [36] & 2018 & & $x$ & $x$ & & $x$ \\
\hline
\end{tabular}

Based on the summary in Table 1, none of the studies provides a performance comparison of different methodologies for solving a large-scale supply chain model. The main contribution of this research can be summarized as follows: First, it makes a contribution to biomass supply chain planning research. The insights obtained from a case study based in Vietnam, an agricultural country, can be applied to the design of biomass supply chains in other regions. Second, this research proposes three methodologies for determining a solution for the biomass supply chain. A comprehensive performance comparison of the proposed methods is provided with managerial insights. 


\section{Problem Statement}

In general, there are many types of biomass available from many suppliers that can be collected and transported to biomass plants in order to generate electricity and satisfy demand, as shown in Figure 1. Due to their locations, each supplier has specific types of available biomass. As a result, biomass supply capacity varies by supplier and type of biomass. Besides, the availability of biomass depends on the season, and available quantities vary throughout the year. The peak season for some types of biomass may be off-season for others.

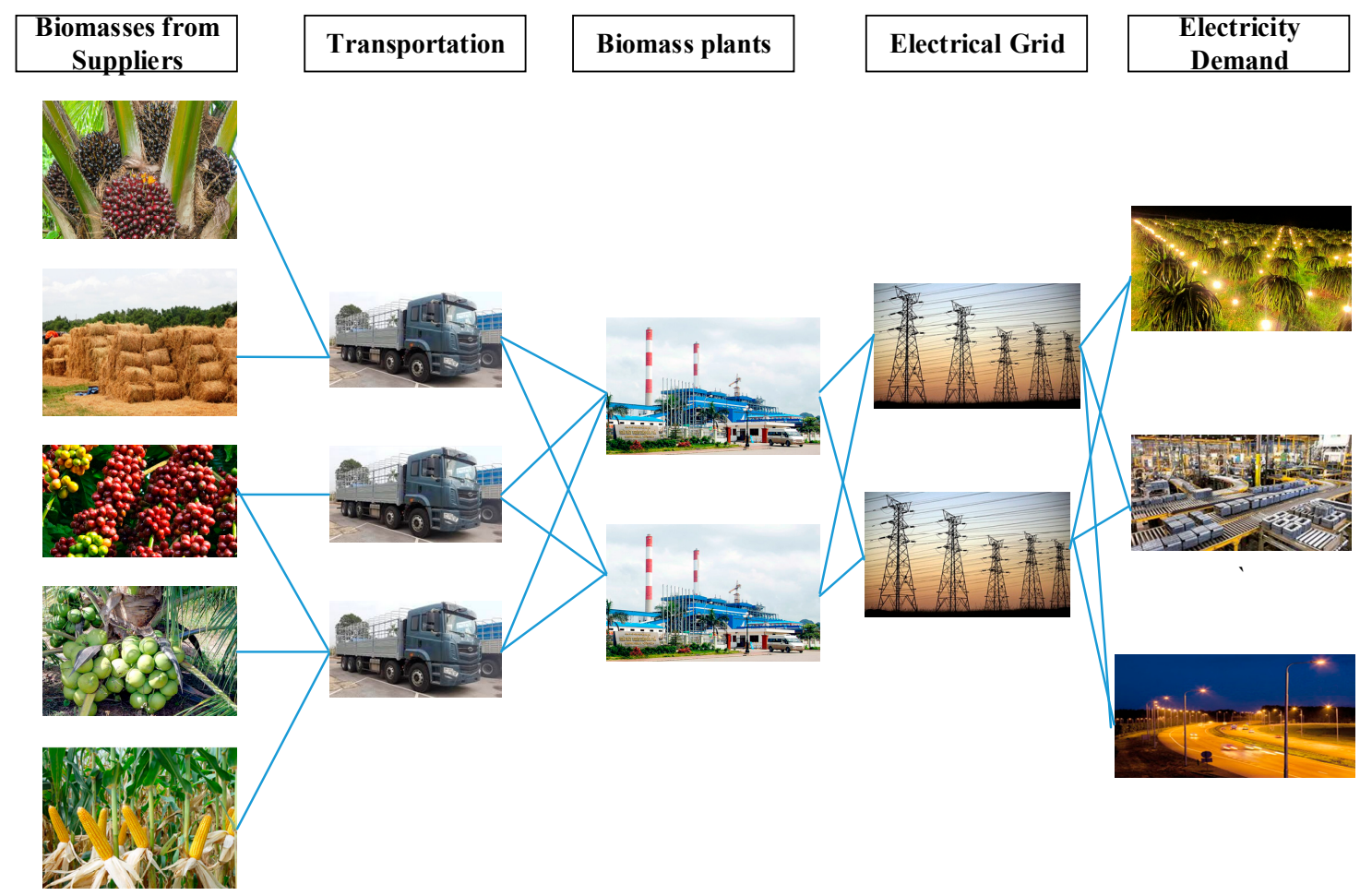

Figure 1. Biomass supply chain network.

In addition, different types of biomass have different characteristics. For example, heat value is one important factor that impacts the amount of energy biomass can generate. Furthermore, different types of biomass require different preprocessing procedures in order to maintain certain properties, such as water content, ash content, and level of contaminants, so they do not violate the technical limitation of the combustion chamber. Also, biomass from different suppliers needs to be transported to plants based on the available transportation mode. Furthermore, purchasing cost and transportation cost vary by type of biomass. The biomass plant generates electricity with a limited capacity from different types of biomass. The plant can keep biomass as inventory for use in the future, with a specified holding cost for each type of biomass. More details on the biomass supply chain model can be found in Duc and Nananukul [16]. The electricity demand in each period must be satisfied, and there is a penalty cost for lost demand. In this research, uncertainty in suppliers' capacity and electricity demand is considered in the biomass supply chain planning. When the amount of biomass, number of suppliers, and plant and uncertainty factors increase, the complexity of the problem increases significantly. Special methodology is required to determine a solution for the biomass supply chain planning problem that minimizes operating costs with a practical run time. In order to determine a practical solution for the biomass supply chain problem, three methodologies are proposed in this research, and are introduced in Section 4. 


\section{Advanced Methodologies}

In this section, advanced methodologies based on a stochastic optimization model, parameter optimization with simulation model, and simulation-based optimization are described.

\subsection{Stochastic Optimization Model}

The stochastic model is extended from Duc and Nananukul [16], who considered uncertainty from supplier capacity; note that the percentage used to define the values of supplier capacity for low and high scenarios is $10 \%$. The probability of scenarios for uncertain supplier capacity is the same as the probability of scenarios for demand.

The main indices that represent periods in a year, types of biomass, suppliers, biomass plants, and scenarios of uncertain demand and uncertain supplier capacity are listed as follows:

i Biomass

j Supplier

$t$ Time period

$f \quad$ Biomass plant

$z \quad$ Uncertain demand scenario

w Uncertain supplier capacity scenario

$S=\{1,2, \ldots, S\} \quad$ Set of suppliers

$T=\{1,2, \ldots, T\} \quad$ Set of periods

$B=\{1,2, \ldots, B\} \quad$ Set of biomass types

$F=\{1,2, \ldots, F\} \quad$ Set of biomass plants

$Z=\{1,2, \ldots, Z\} \quad$ Set of scenarios of demand

$W=\{1,2, \ldots, W\} \quad$ Set of scenarios of supplier capacity

The notations for the parameters are summarized as follows:

$p \quad$ Electricity sale price

Pur $_{i j}$ Purchasing cost of biomass $i$ from supplier $j$

$\mathrm{Tc}_{i} \quad$ Transportation unit cost of biomass $i$

$h_{i} \quad$ Inventory holding cost of biomass $i$

$F_{f} \quad$ Factory fixed cost of biomass plant $f$

$D_{t z} \quad$ Monthly electricity demand period in $t$ of scenario $z$

$S_{i j}{ }^{\text {tw }}$ Maximum quantity of biomass $i$ of supplier $j$ in period $t$ of scenario $w$

$d_{i f} \quad$ Distance between supplier $j$ and biomass plant $f$

$M \quad$ Maximum number of biomass plants

$C_{f} \quad$ Capacity of biomass plant $f$

$r_{i} \quad$ Ratio used to convert tons of biomass $i$ to MWh

$\mathrm{Pbd}_{\mathrm{z}}$ Probability of scenario $z$ of uncertain demand

$P b s_{w}$ Probability of scenario $w$ of uncertain supplier capacity

There are five categories of decision variables, as follows:

$Y_{f} \quad$ Decision to open or close biomass plant $f$, binary

$X_{i j f} t z w$ Biomass quantity $i$ purchased from supplier $j$ at plant $f$ in period $t$ for scenario $z$ ofdemand and scenario $w$ of supplier capacity

$I_{i f}{ }^{t z w} \quad$ Inventory level of biomass $i$ at plant $f$ carried in period $t$ for scenario $z$ of demand andscenario $w$ of supplier capacity 
$U_{i f}^{t z w} \quad$ Biomass quantity $i$ used at plant $f$ in period $t$ for scenario $z$ of demand and scenario $w$ of supplier capacity

$L_{t z w} \quad$ Lost demand in period $t$ for scenario $z$ of demand and scenario $w$ of supplier capacity

The objective function in Equation(1) includes the benefit from satisfying electricity demand and subtracts total cost: factory fixed cost, penalty cost (if the demand cannot be satisfied), purchasing cost, transportation cost, and inventory holding cost.

Each term from (1) is described as follows:

Profit from Demand satisfaction $=\sum_{t=1}^{t=|T|} p \times\left(D_{t z}-L_{t z z}\right)$

Penalty cost from lost demand $=\sum_{\mathrm{t}=1}^{\mathrm{t}=|T|} p \times L_{t z w}$

Biomass purchasing cost $\quad=\sum_{\mathrm{t}=1}^{\mathrm{t}=|\mathrm{T}|} \sum_{\mathrm{i}=1}^{\mathrm{i}=|\mathrm{B}|} \sum_{\mathrm{j}=1}^{\mathrm{j}=|\mathrm{S}|} \sum_{\mathrm{f}=1}^{\mathrm{f}=|\mathrm{F}|} \operatorname{Pur}_{\mathrm{ij}} \times X_{\mathrm{ijf}}^{\mathrm{tzw}}$

Transportation cost $=\sum_{\mathrm{t}=1}^{\mathrm{t}=|\mathrm{T}|} \sum_{\mathrm{i}=1}^{\mathrm{i}=|\mathrm{B}|} \sum_{\mathrm{j}=1}^{\mathrm{j}=|\mathrm{S}|} \sum_{\mathrm{f}=1}^{\mathrm{f}=|\mathrm{F}|} \mathrm{d}_{\mathrm{jf}} \times \mathrm{Tc}_{\mathrm{i}} \times \mathrm{X}_{\mathrm{ijf}}^{\mathrm{fzw}}$

Inventory holding cost $=\sum_{\mathrm{t}=1}^{\mathrm{t}=|\mathrm{T}|} \sum_{\mathrm{i}=1}^{\mathrm{i}=|\mathrm{B}|} \sum_{\mathrm{j}=1}^{\mathrm{j}=|\mathrm{S}|} \sum_{\mathrm{f}=1}^{\mathrm{f}=|\mathrm{F}|} \mathrm{h}_{\mathrm{ij}} \times \mathrm{I}_{\mathrm{if}}^{\mathrm{tzw}}$

Factory fixed cost $=\sum_{f=1}^{f=|F|} Y_{f} \times F_{f}$

Maximize:

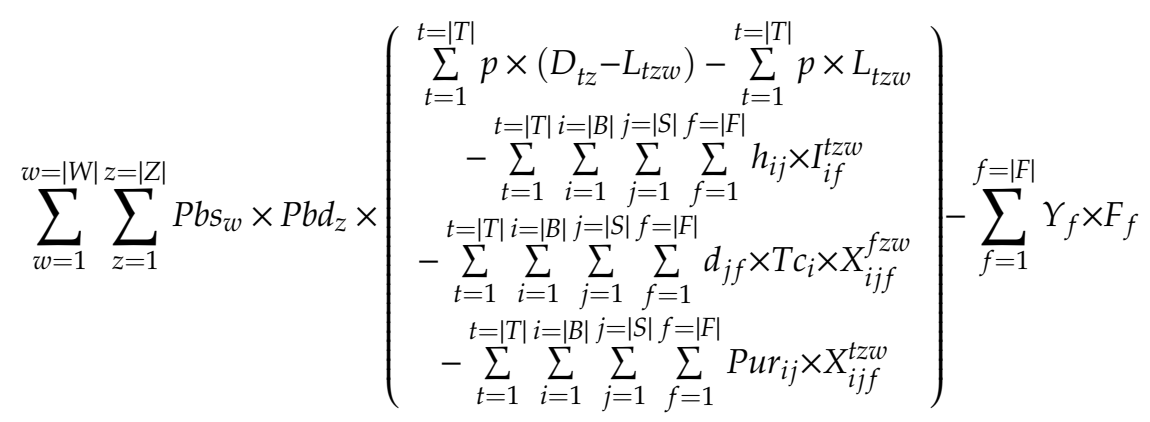

All mathematical constraints are presented next. There are altogether six constraints.

$$
\begin{gathered}
\sum_{i=1}^{i=|B| f=|F|} \sum_{f=1}^{t z z w} \times r_{i}+L_{t z w} \geq D_{t z} \quad \forall t \in T, \forall z \in Z, \forall w \in W \\
\sum_{i=1}^{i=|B|} U_{i f}^{t z w} \times r_{i} \leq Y_{f} \times C_{f} \quad \forall t \in T, \forall f \in F, \forall z \in Z, \forall w \in W \\
U_{i f}^{t z w} \leq I_{i f}^{(t-1) z w}+\sum_{j=1}^{j=|S|} X_{i j f}^{t z z w} \quad \forall t \in T, \forall i \in B, \forall f \in F, \forall z \in Z, \forall w \in W \\
I_{i f}^{t z w w}=I_{i f}^{(t-1) z w}+\sum_{j=1}^{j=|S|} X_{i j f}^{t z w}-U_{i f}^{t z w} \quad \forall t \in T, \forall i \in B, \forall f \in F, \forall z \in Z, \forall w \in W \\
\sum_{f=1}^{f=|F|} X_{i j f}^{f z w} \leq S_{i j}^{t w w} \quad \forall t \in T, \forall j \in S, \forall i \in B, \forall z \in Z, \forall w \in W \\
X_{i j f}^{t z w}, I_{i f}^{t z w}, U_{t i f}^{t z w}, L_{t z w} \geq 0 \quad \forall t \in T, \forall j \in S, \forall i \in B, \forall f \in F, \forall z \in Z, \forall w \in W
\end{gathered}
$$


Equation (2) relates the amount of electricity demand with the amount of electricity generated and lost demand. Equation (3) presents the limitation of capacity at the biomass plant. Equation (4) presents the used biomass in each period. Biomass used in a period is less than or equal to inventory from the previous period and biomass shipped to factory in the current period. Equation (5) is the inventory balance constraint. Equation (6) defines the capacity of the supplier. The amount of biomass ordered from the supplier must satisfy the supplier's capacity. Equation (7) limits the number of plants that can be used.

\subsection{Simulation Model}

In this research, a simulation model for the biomass supply chain was created by using Matlab Simulink. A block diagram of the simulation model of the biomass supply chain system, which considers electricity demand, supplier, biomass plant, inventory at biomass plant, and transportation between suppliers and biomass plants, is shown in Figure 2.

The notations of parameters from Figure 2 are described as follows:

Demand $_{t} \quad$ Actual demand in period $t$

Sale $t_{t} \quad$ Demand that can be satisfied in period $t$

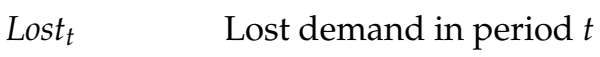

Generated $_{t} \quad$ Electricity generated in period $t$

Factory:

$E P \_G e n_{f t} \quad$ Amount of planned electricity generated from plant $f$ in period $t$

$E A_{-} G e n_{f t} \quad$ Actual electricity generated from plant $f$ in period $t$

$E B P \_G e n_{i f t} \quad$ Planned electricity generated from plant $f$ by biomass $i$ in period $t$

$E B A_{-} G e n_{i f t}$ Actual electricity generated from plant $f$ by biomass $i$ in period $t$

FPer ft $_{f t} \quad$ Proportion of factory $f$ used to generate electricity in period $t$

ORatiot $\quad$ Order ratio in period $t$

$\operatorname{OrderF}_{i f t} \quad$ Amount of biomass $i$ ordered from plant $f$ in period $t$

Supplier:

S_C $p_{i j t} \quad$ Supply capacity of biomass $i$ at supplier $j$ in period $t$

BSF_Del $l_{i j t} \quad$ Amount of biomass $i$ delivered from supplier $j$ to $\operatorname{plant} f$ in period $t$

SPer $_{j f t} \quad$ Proportion of biomass from supplier $j$ at factory $f$ in period $t$

Biomass:

BPer $_{i f t} \quad$ Proportion of biomass $i$ used to generate electricity at plant $f$ in period $t$

Used $_{i f t} \quad$ Amount of biomass $i$ used to generate electricity at plant $f$ in period $t$ 


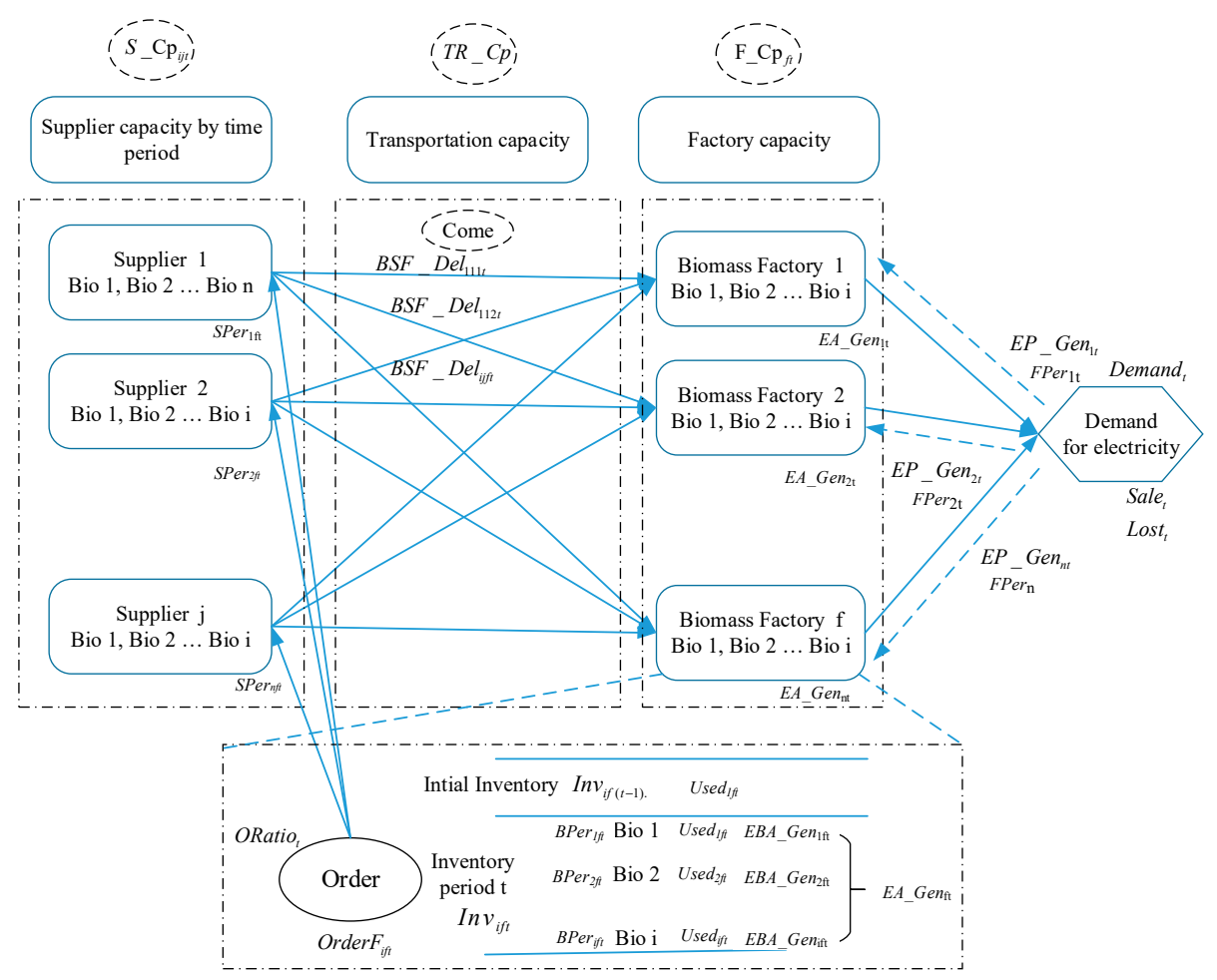

Figure 2. Block diagram of a simulation model for biomass supply chain.

Customer demand is represented by monthly electricity consumption. From the simulation model, the system tries to satisfy the demand as much as possible, because lost demand $\left(\right.$ Lost $\left._{t}\right)$ comes with a penalty cost. Besides, the system also needs to consider relevant costs, such as inventory cost, transportation cost (including loading and unloading costs), and purchasing cost. The demand $\left(\right.$ Demand $\left._{t}\right)$ for electricity is stochastic, and the sale (Sale $)_{t}$ amount fulfilling demand depends on the sum of actual generated electricity $\left(E A_{-} G e_{f t}\right)$ from one or more factories using different types of biomass $\left(E B A \_G e n_{i f t}\right)$. The electricity can be generated based on the available biomass and is limited by plant capacity $\left(F_{-} C p_{f t}\right)$. In the system, electricity is considered an unstock product, where the sale amount is the minimum between the demand and the generated electricity:

$$
\text { Sale }_{t}=\operatorname{Min}\left(\text { Demand }_{t}, \text { Generated }_{t}\right)
$$

Lost demand is defined by the following formulas:

$$
\text { Lost }_{t}=\text { Demand }_{t}-\text { Generated }_{t}
$$

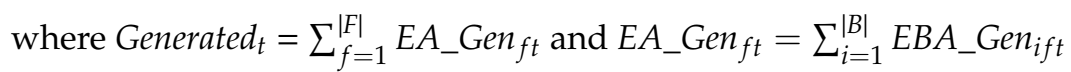

$$
\begin{gathered}
\text { Demand }_{t}=\sum_{f=1}^{|F|} \text { Fper }_{t f} \times E P_{-} \text {Gen }_{t f} \text { and } \sum_{f=1}^{|F|} \text { Fper }_{t f}=1 \\
\text { EA_Gen } n_{f t} \leq E P \_G e n_{f t} ; E A_{-} G e n_{f t} \leq F_{-} C p_{f t}
\end{gathered}
$$

Initially, the decision related to the biomass order quantity is based on the forecasted demand of the period. The amount of biomass used at each plant in a period depends on the demand and the inventory of biomass from the previous period. The order ratio $\left(\mathrm{ORatio}_{t}\right)$ enables the system to set the level of biomass to be kept in inventory for use in future periods. Although the plant can order biomass from suppliers $\left(\operatorname{Order} F_{i f t}\right)$, the amount it can receive depends on the suppliers' capacity in each period. In addition, the total order from plants must be less than the suppliers' capacity $\left(S_{-} C p_{i j t}\right)$. 
Suppliers try to satisfy orders from plants as much as possible. A supplier decides the percentage of biomass delivered to a plant based on the proportion ordered from the plant when there are limited resources. The transporting capability of all routes from suppliers to plants (BSF_Del $l_{i j f t}$ ) is limited by the transportation capacity (TR_Cp). In this research, biomass is transported mainly by truck. Because biomass can be ordered from different suppliers (SOrder $r_{i j f}$ ), at a plant, the proportion of biomass ordered from different suppliers is defined by $S P e r_{j f t}$. The relationship among the variables is summarized as follows:

$$
\text { Order }_{i f t}=\text { ORatio }_{t} \times \text { OrderF }_{i f t}
$$

While $\sum_{\mathrm{f}=1}^{|\mathrm{F}|}$ SOrder $_{\mathrm{ijft}} \leq \mathrm{S} \_C \mathrm{p}_{\mathrm{ijt}}$ and $\sum_{\mathrm{f}=1}^{|\mathrm{F}|} \mathrm{BSF}_{-} \mathrm{Del}_{\mathrm{ijft}} \leq \mathrm{S} \_C \mathrm{p}_{\mathrm{ijt}}$

$$
\begin{gathered}
\text { BSF_Del } i_{j f t} \leq \text { TR_Cp. } \\
\text { SOrder }_{i j f t}=\sum_{f=1}^{|F|} \text { Order }_{i f t} \times \text { Sper }_{j f t} \text { While }^{|S|} \text { Sper }_{j f t}=1
\end{gathered}
$$

At a plant, the amount of biomass $i$ used to generate electricity in period $t$ is represented by Used $_{i f t}$ and the amount of electricity generated is $E B A_{-} G_{e n} n_{i f t}$. The proportion of biomass used to generate electricity is defined by $B P e r_{i f t}$. The remaining biomass is stocked as inventory $\left(I n v_{i f t}\right)$ for use in future periods.

$$
\begin{aligned}
& E P_{-} G e n_{f t}=\sum_{i=1}^{|B|} E B P_{-} G e n_{i f t} \times B P e r_{i f t} \text { and } E B A_{-} G_{e n} n_{i f t}=U_{s e d} d_{i f t} \times r_{i} ; \sum_{i=1}^{|B|} \text { Bper }_{i f t}=1 ; \\
& I n v_{i f t}=\operatorname{Inv}_{i f(t-1)}+\sum_{j=1}^{|S|} B S F_{-} D l_{i j f t}-U_{s e d_{i f t}}
\end{aligned}
$$

\subsection{Simulation-Based Optimization (Hybrid Method)}

In this section, a description of the simulation-based optimization approach is provided. The proposed method consists of two models, simulation and optimization. The connection between the models is shown in Figure 3. The simulation model can represent uncertainty from different factors and evaluate the performance of the system, while the optimization model can optimize system performance based on the required operational constraints. The interaction between the two models continues iteratively until the stopping condition is satisfied. The details of the proposed simulation-based optimization approach are described below.

Step 1: A simulation model is developed to capture all uncertainty from demand and supplier capacity. Their values are randomly generated based on the predefined probability distributions, which were determined using historical data.

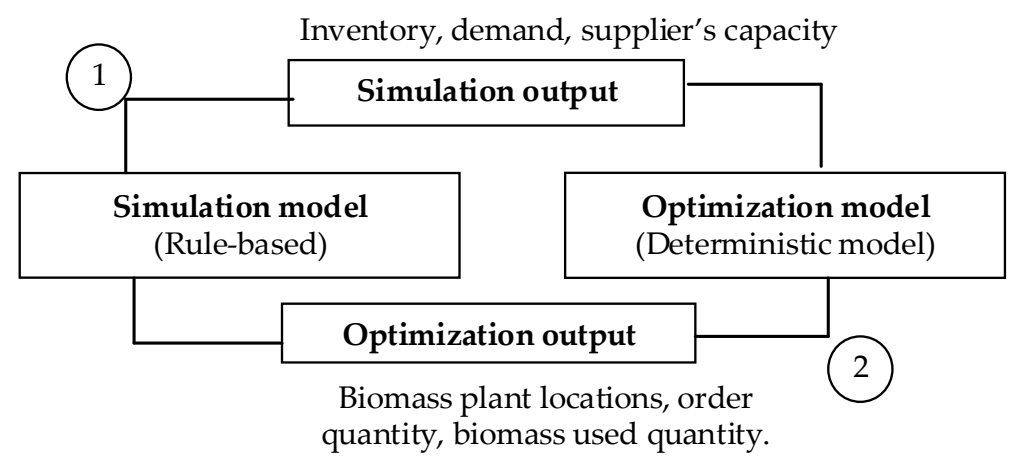

Figure 3. Interaction between simulation and optimization models.

Step 2: A mixed-integer linear programing model for biomass supply chain planning is developed, in which demand and supplier capacities in all periods are considered deterministic and the values are set equal to the mean values of each scenario. The optimization model determines biomass plant 
location, order quantity, and quantity of biomass used in the considered period. Then, the values are passed back as input to the simulation model.

Step 3: The simulation model sets biomass plant location, order quantity, and quantity of biomass used according to the result from the optimization model.

Step 4: The procedure repeats until all periods are considered and the number of simulation runs is satisfied.

\section{Case Study}

In this section, a case study from the north central coast of Vietnam is considered. The optimization models were implemented and solved by using the IBM ILOG CPLEX optimization studio version 12.6.1.0, where the simulation model was implemented by Matlab Simulink. The models were executed using a computer with an Intel Core I7-6550U CPU @ $2.5 \mathrm{GHz}$ and 8.0 GB memory with Windows 10 pro 64-bit.

Historical electricity demand was provided by the Vietnam Electricity Corporation, and future demand was forecasted from the historical data. The forecast method was based on exponential smoothing with alpha $=0.96$ and beta $=0.99$, where the error measurement based on Mean Absolute Deviation (MAD) was used. The purchasing cost of biomass was collected from quoted prices from different available government resources. Transportation cost was based on standard cost for a six-wheel truck. The potential biomass plant locations are in the available industrial zones throughout the region. Supplier locations are assumed to be at the centers of provinces. Distances between suppliers and plants are based on real distances identified from Google Maps, which were then used to generate a distance matrix. The levels and probabilities for the scenarios of electricity demand and supply capacity were generated based on historical data, with three levels defined for scenarios of electricity demand and supply capacity. The values of demand for low and high scenarios were defined as $50 \%$ below and above the medium demand (actual demand), while the percentage used to define the values of supplier capacity for low and high scenarios is 10\%. Each scenario had an equal chance to occur, and the probability of each scenario was set to 0.33 . The biomass plant capacity was assumed to be 540,000 MWh per month with fixed cost equal to 694 million United States Dollar (USD). More details of how the relevant data for the model were prepared can be found in [16].

\subsection{Parameter Optimization Method}

The response optimization function in Matlab Simulink was used to optimize the values of three key parameters: biomass percentage $\left(\mathrm{BPer}_{i f t}\right)$, supplier's percentage $\left(\mathrm{SPer}_{\mathrm{jft}}\right)$, and order ratio $\left(\mathrm{ORatio}_{t}\right)$. The ranges were set as follows: biomass percentage between 0 and 1 with scale 0.01 ; order ratio between 1 and 2 with scale 0.01 ; and supplier's percentage between 0 to 1 with scale 0.01 . Note that since the capacity of a plant is sufficient to satisfy the electricity demand, as a result, $|\mathrm{F}|=1$ for the north central coast region.

To illustrate the scalability issue of the parameter optimization method, two cases were considered. The first considers only one supplier to supply biomass to the plant, and the second considers multiple suppliers.

(a) Single supplier case

The result from the parameter optimization method when a single supplier is considered is shown in Table 2.

The parameter optimization method adjusted the biomass used percentage in order to satisfy customer demand at the lowest cost. However, the method is not able to coordinate the decisions in different periods; as a result, there is lost demand in the system, with large transportation cost based on the attempt to satisfy demand in each period separately. 
Table 2. Result from parameter optimization method (single supplier case).

\begin{tabular}{ccc}
\hline & (USD) & \% of Total Cost \\
\hline Total cost & $7,599,535$ & \\
\hline Purchasing & $4,139,899$ & 54 \\
\hline Transportation & $3,064,603$ & 40 \\
\hline Inventory & 240,102 & 3 \\
\hline Lost demand & 154,932 & 2 \\
\hline
\end{tabular}

Due to the sufficient amount of biomass through the years, when the parameters are optimized, types of biomass with low price, low transportation cost, and high heat value were chosen in the solution. The examples are biomass 2, 4, 8, and 9. The order ratio for the single supplier case is shown in Table 3 .

In the first two periods, the order ratios are low because the system can rely on the initial inventory. In April, May, June, and July, which are considered peak harvesting season, the order ratios are increased in order to maintain sufficient inventory for later periods.

Table 3. Order ratio (single supplier case) from parameter optimization method.

\begin{tabular}{|c|c|c|c|c|c|c|c|c|c|c|c|c|}
\hline & Jan & Feb & Mar & Apr & May & Jun & Jul & Aug & Sep & Oct & Nov & Dec \\
\hline ORatiot $_{t}$ & 1.08 & 1.08 & 1.10 & 1.09 & 1.33 & 1.50 & 1.50 & 1.10 & 1.10 & 1.10 & 1.10 & 1.10 \\
\hline
\end{tabular}

(b) Multiple suppliers case

When considering multiple suppliers (six suppliers), the number of parameters increases significantly. As a result, the parameter optimization method loses efficiency, as shown in Table 4. The total cost was increased by $10 \%$ and the cost from lost demand was $35 \%$ of the total cost. Note that the solution is not optimal due to increased interaction among the parameters, which makes the optimization process much more complicated and requires more run time.

Table 4. Result from parameter optimization method (multiple suppliers).

\begin{tabular}{ccc}
\hline & (USD) & \% of Total Cost \\
\hline Total cost & $12,721,517$ & \\
\hline Purchasing & $2,984,534$ & 23 \\
\hline Transportation & $5,062,852$ & 40 \\
\hline Inventory & 178,248 & 1 \\
\hline Lost demand & $4,495,883$ & 35 \\
\hline
\end{tabular}

The model tries to use the types of biomass with low price and low transportation cost but high heat value, such as biomass 2 and 8, while decreasing the use of biomass 1, as shown in Figure 4. The order ratio is summarized in Table 5 .

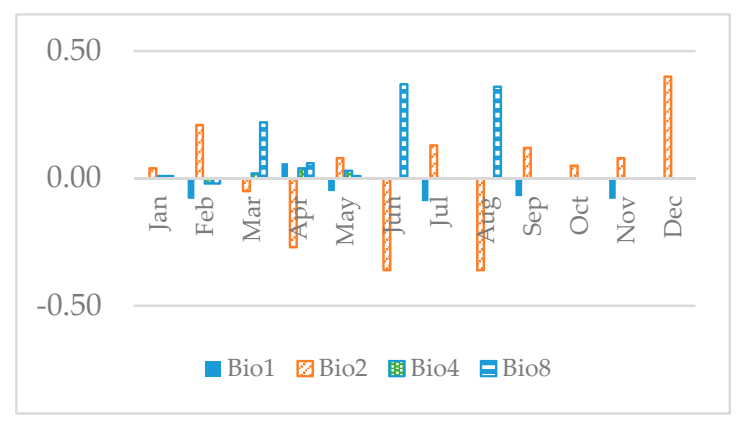

Figure 4. Difference of biomass proportions from multiple suppliers and single supplier. 
Table 5. Order ratio for multiple suppliers from parameter optimization method.

\begin{tabular}{lllllllllllll}
\hline & Jan & Feb & Mar & Apr & May & Jun & Jul & Aug & Sep & Oct & Nov & Dec \\
\hline ORatio $_{t}$ & 1.09 & 1.97 & 1.40 & 2.00 & 1.03 & 1.03 & 1.19 & 1.09 & 1.04 & 1.23 & 1.42 & 1.10 \\
\hline
\end{tabular}

The order ratios for multiple suppliers fluctuate wildly. The order ratios are low in January, May, June, and September, and high in other periods. However, a changing trend cannot be observed; this is one of the disadvantages of the parameter optimization method. When the number of parameters is large, the method is not able to search through all neighborhoods of the solution space.

\subsection{Simulation-Based Optimization Method (Hybrid Method)}

The result from the simulation-based optimization method is summarized in Table 6. In terms of operation cost, this method provides better cost saving than parameter optimization. Due to the ability to take into account the operation in the following periods, the percentage of lost demand penalty cost is near zero. The total cost for the simulation-based optimization method is $75 \%$ and $45 \%$ for single supplier and multiple suppliers, respectively, compared to parameter optimization, because the decisions related to inventory and lost demand can be coordinated in different periods.

Table 6. Results from simulation-based optimization method (multiple suppliers).

\begin{tabular}{|c|c|c|c|c|}
\hline (USD) & $\begin{array}{c}\text { Average of } \\
20 \text { Simulation Runs }\end{array}$ & $\begin{array}{c}\text { Average of } \\
30 \text { Simulation Runs }\end{array}$ & $\begin{array}{c}\text { Average of } \\
40 \text { Simulation Runs }\end{array}$ & $\%$ of Total Cost \\
\hline Total cost & $5,314,524$ & $5,667,128$ & $5,694,466$ & \\
\hline Purchasing & $2,993,653$ & $3,142,026$ & $3,152,942$ & 55.37 \\
\hline Transportation & $2,268,329$ & $2,478,024$ & $2,493,224$ & 43.78 \\
\hline Inventory & 52,294 & 46,801 & 48,018 & 0.84 \\
\hline Lost demand & 249 & 277 & 282 & 0.0049 \\
\hline
\end{tabular}

The simulation-based optimization method gives acceptable results due to the following assumption. In the optimization model, demand and supplier capacity in all periods are considered deterministic and the values are set equal to the mean values of each scenario. However, from the simulation model, the demand in some periods could be lower than the mean value. As a result, that system carries inventory for use in the following periods. In the case where the demand generated by the simulation model is higher than the mean value, lost demand may occur. Based on the result, the amount of lost demand is very small due to the abundance of biomass in this region. One of the disadvantages of this method is that when the demand suddenly increases in some periods, the method must utilize biomass from remote suppliers or with high purchasing cost. This will increase transportation and purchasing costs.

\subsection{Managerial Insights}

A summary of the results from all methods is provided in Table 7. The run time from stochastic optimization was 17 seconds, which was the fastest. The run time from the simulation-based method was only 3 seconds per run (period). The run time from the parameter optimization method takes more than 30 minutes per run (period) due to a significant increase in the number of parameters.

When comparing the results from all methods, the solution from the stochastic optimization model is best, if the problem can be solved to optimality. The stochastic optimization model provides the lowest inventory cost without lost demand. However, the result from simulation-based optimization is acceptable when compared to the solutions from parameter optimization. Inventory cost from the simulation-based method is $19.98 \%$ of the cost from parameter optimization based on multiple suppliers. Finally, the amount of lost demand is significantly different among all methods. The amount of lost demand from the stochastic model is zero. Although there exists lost demand from the 
simulation-based optimization method, the amount is very small when compared with other costs, as shown in Table 6.

Table 7. Summary of results from all methods.

\begin{tabular}{cccc}
\hline (USD) & $\begin{array}{c}\text { Parameter Optimization } \\
\text { (Multiple Suppliers) }\end{array}$ & $\begin{array}{c}\text { Simulation-Based Optimization } \\
\text { (Multiple Suppliers) }\end{array}$ & $\begin{array}{c}\text { Stochastic Optimization } \\
\text { (Multiple Suppliers) }\end{array}$ \\
\hline Total cost & $\mathbf{1 2 , 7 2 1 , 5 1 7}$ & $\mathbf{5 , 6 9 4 , 4 6 6}$ & $\mathbf{5 , 4 7 1 , 8 1 8}$ \\
\hline Purchasing & $2,984,534$ & $3,152,942$ & $2,970,677$ \\
\hline Transportation & $5,062,852$ & $2,493,224$ & $2,475,719$ \\
\hline Inventory & 178,248 & 48,018 & 25,422 \\
\hline Lost demand & $4,495,883$ & 282 & 0 \\
\hline Runtime & $>30 \mathrm{~min} / \mathrm{run}$ & $3 \mathrm{~s} / \mathrm{run}$ & $17 \mathrm{~s}$ \\
\hline Plant location & $\mathrm{F} 86$ & $\mathrm{~F} 87$ & $\mathrm{~F} 87$ \\
\hline
\end{tabular}

Table 8 reports the result from the stochastic optimization model based on all regions in Vietnam. Column 1 represents the region; columns 2 and 3 specify the number of suppliers and candidate locations for factories considered in the model; columns 4 and 5 report the number of decision variables and constraints of the model; and column 6 reports the run time. The scale of problems is based on the number of suppliers and factory candidates. Particularly, those problems in Northeast, Northwest, Central Highland, and North Central Coast are classified as small problem. Whereas, Mekong River Delta, Southeast, South Central Coast, and Red River Delta are considered medium problem. North Vietnam is classified as large problem. In general, the result from the stochastic model is always good due to its ability to consider the constraints from all periods at once. However, for a large-scale problem with the limitation of run time and computer configuration, the solution might not exist. The stochastic optimization model failed to solve the problem for the North Vietnam region (combination of Northeast, Northwest, and Red River Delta), as shown in Table 8, due to an "out of memory" issue.

For parameter optimization, when the number of parameters is small, this is a good method to improve the result from the simulation model. However, when the number of parameters increases, parameter optimization can be expensive and unwieldy, because it takes more samples to find a good solution.

Table 8. Run time from stochastic optimization for all regions in Vietnam.

\begin{tabular}{cccccc}
\hline Region & \#Supplier & \#Factory & \#Variable & \#Constraint & Run Time (s) \\
\hline Northeast & 9 & 17 & 244,314 & 59,509 & 27.0 \\
\hline Northwest & 6 & 5 & 52,494 & 21,925 & 9.2 \\
\hline Central Highland & 5 & 6 & 55,195 & 23,437 & 8.0 \\
\hline Mekong River Delta & 13 & 32 & 625,677 & 106,813 & 64.8 \\
\hline North Central Coast & 6 & 12 & 125,833 & 41,581 & 16.0 \\
\hline Southeast & 6 & 35 & 366,804 & 106,165 & 263.2 \\
\hline South Central Coast & 8 & 32 & 418,317 & 100,333 & 166.8 \\
\hline Red River Delta & 10 & 57 & 892,786 & 173,125 & 470.0 \\
\hline North Vietnam & 25 & 79 & $2,773,088$ & 254,341 & OM \\
\hline & & OM, out of memory. & &
\end{tabular}

The results for problems from other regions based on the simulation-based optimization method are shown in Table 9. In this method, the optimization model is set as a deterministic model. As a result, the method helps to decrease the number of variables and constraints in the optimization model. For example, the problem related to the North Vietnam region has only 924,380 variables and 84,781 constraints that need to be considered. 
Table 9. Results from simulation-based optimization for all regions in Vietnam. Simulation-based optimization (SBO); Stochastic optimization (Opt) (Unit: USD).

\begin{tabular}{|c|c|c|c|c|c|c|c|}
\hline Region & Type of Cost & Total Cost & $\begin{array}{l}\text { Purchasing } \\
\text { Cost }\end{array}$ & $\begin{array}{l}\text { Transportation } \\
\text { Cost }\end{array}$ & $\begin{array}{l}\text { Inventory } \\
\text { Cost }\end{array}$ & $\begin{array}{c}\text { Lost } \\
\text { Demand }\end{array}$ & Gaps \\
\hline \multirow{2}{*}{ Northeast } & SBO & $6,810,120$ & $4,812,702$ & $1,960,736$ & 36,062 & 620 & \multirow{2}{*}{$0.59 \%$} \\
\hline & Opt & $6,770,169$ & $4,749,170$ & $2,007,344$ & 13,655 & 0 & \\
\hline \multirow{2}{*}{ Northwest } & SBO & $2,832,047$ & $1,915,408$ & 866,589 & 49,752 & 297 & \multirow{2}{*}{$1.37 \%$} \\
\hline & Opt & $2,793,895$ & $1,911,594$ & 833,322 & 48,979 & 0 & \\
\hline \multirow{2}{*}{$\begin{array}{l}\text { Central } \\
\text { Highland }\end{array}$} & SBO & $1,785,168$ & $1,684,645$ & 99,758 & 21 & 743 & \multirow{2}{*}{$2.49 \%$} \\
\hline & Opt & $1,741,853$ & $1,648,477$ & 93,194 & 182 & 0 & \\
\hline \multirow{2}{*}{$\begin{array}{l}\text { Mekong River } \\
\text { Delta }\end{array}$} & SBO & $8,365,685$ & $7,029,384$ & 981,653 & 63,133 & 291,515 & \multirow{2}{*}{$3.16 \%$} \\
\hline & Opt & $8,109,510$ & $7,113,200$ & 987,720 & 8590 & 0 & \\
\hline \multirow{2}{*}{$\begin{array}{l}\text { North Central } \\
\text { Coast }\end{array}$} & SBO & $5,694,466$ & $3,152,942$ & $2,493,224$ & 48,018 & 282 & \multirow{2}{*}{$4.07 \%$} \\
\hline & Opt & $5,471,818$ & $2,970,677$ & $2,475,719$ & 25,422 & 0 & \\
\hline \multirow{2}{*}{ Southeast } & SBO & $67,242,138$ & $17,527,546$ & $8,373,536$ & 60,323 & $41,280,733$ & \multirow{2}{*}{$4.83 \%$} \\
\hline & Opt & $64,145,845$ & $17,403,914$ & $8,023,045$ & 8,736 & $38,710,150$ & \\
\hline \multirow{2}{*}{$\begin{array}{l}\text { South Central } \\
\text { Coast }\end{array}$} & SBO & $13,238,192$ & $8,171,592$ & $5,004,807$ & 49,623 & 12,169 & \multirow{2}{*}{$4.89 \%$} \\
\hline & Opt & $12,621,466$ & $7,749,254$ & $4,844,672$ & 27,541 & 0 & \\
\hline \multirow{2}{*}{ Red River Delta } & SBO & $42,177,964$ & $11,900,178$ & $5,494,603$ & 108,508 & $24,674,676$ & \multirow{2}{*}{$8.41 \%$} \\
\hline & Opt & $38,904,973$ & $11,531,123$ & $5,431,544$ & 22,828 & $21,919,478$ & \\
\hline
\end{tabular}

The lowest and highest gaps in the results between simulation-based and stochastic optimization are $0.59 \%$ and $8.41 \%$, respectively. The simulation-based optimization method can provide solutions close to the optimal solutions (gap less than $4.5 \%$ ) from the stochastic model for regions with small number of suppliers and biomass plant candidates such as Northeast, Northwest, and Central Highland, or regions with abundant biomass supply capacity and low demand such as Mekong River Delta and North Central Coast. Based on the simulation-based optimization model, the demand and supply capacity of future periods were set to the values from medium scenarios; as a result, once the observed demand suddenly increases or supply capacity decreases, lost demand could occur in some periods. In regions such as Northeast, Northwest, Highland, North Central, South Central, Red River Delta, and Mekong River Delta, the cost from lost demand compared to the total cost is very small (less than $3.48 \%$ ), which is insignificant. In regions such as Southeast and Red River Delta, the model considered a trade-off between biomass plant investment, which is 694 million USD per factory, and the amount of lost demand, which is 21.9 million USD in Red River Delta and 38.7 million USD in Southeast. The amount of lost demand from simulation-based optimization is within $6.64 \%$ and $12.57 \%$ of the lost demand from stochastic optimization for Red River Delta and Southeast, respectively.

When considering a larger region, North Vietnam, where CPLEX failed to provide the solution due to an "out of memory" issue, the simulation-based optimization method provides a solution as shown in Table 10.

Table 10. Results from simulation-based and stochastic optimization for North Vietnam.

\begin{tabular}{cc}
\hline USD & Simulation-Based Optimization \\
\hline Total cost & $\mathbf{2 9 , 3 1 0 , 9 6 8}$ \\
\hline Purchasing & $18,116,711$ \\
\hline Transportation & $9,947,231$ \\
\hline Inventory & 177,809 \\
\hline Lost demand & $1,069,217$ \\
\hline Run time & Less than $160 \mathrm{~s} / \mathrm{run}$ \\
\hline
\end{tabular}


Although the result from the simulation-based model is not always optimal, the advantage of the method is the ability to generate a high-quality solution within a practical run time; in the first period, it took $160 \mathrm{~s}$ to generate the solution, and in the final period $0.02 \mathrm{~s}$.

The results from this research can be compared with results from other relevant research. For example, Ekşioğlu et al. [13] introduced a mathematical model to determine the number, size, and locations of biorefineries that produce biofuel using the available biomass. The inputs to the model were real data from the State of Mississippi, including the availability of biomass feedstock as well as biomass transportation, inventory, and processing costs. Biomass deterioration, supply seasonality, and supply availability were considered in the model. By using forest residue to generate 40 million gallons per year (MGY) of c-ethanol, the results show that when the transportation cost increased, the model decided to open small-size facilities and spread them out, then each facility was supplied with biomass from forest farms nearby. However, when considering most of the cases used to analyze the problem, the model identified the best plant location (biorefinery size $=50 \mathrm{MGY}$ ) in Covington County, the most abundant biomass area. Similarly, in this research, the plant fixed cost is large compared to other costs. As a result, a small number of plants is used in the solution (one plant for small regions and two for large regions), and they are located close to suppliers that have abundant biomass.

\section{Conclusions and Future Research}

In this study, a biomass supply chain planning model for determining the optimal biomass plant locations and distribution was proposed. The model considers uncertainty in demand and supply capacity. Data from all regions of Vietnam were used in the analysis. In general, the problem tends to increase in scale and complexity when considering more suppliers, plants, and types of biomass. As a result, advanced methodologies based on stochastic programming, simulation and parameter search, and simulation-based optimization were proposed to solve the biomass supply chain planning problem. Parameter search is suitable for small problem only. For small and medium problems, stochastic programming can provide optimal solution. For large problem, simulation-based optimization performs better when considering the quality of the solution and the run time. For example, problems from the North Vietnam region and the whole country cannot be solved by a traditional method such as stochastic optimization due to a dramatic increase in constraints and variables. Based on the provided computational result, even though simulation-based optimization does not guarantee optimality of the solution, it can give a high-quality solution with practical run time and computer configuration. For problems where optimal solutions can be determined, the method can provide solutions with gaps to the optimality between $0.59 \%$ and $8.41 \%$. The simulation-based optimization method proposed in this research contributes to the advancement of large-scale supply chain planning.

The results from the case study in this research can be used as a guide for designing a biomass supply chain in Vietnam. Furthermore, the model can be used to perform sensitivity analysis in order to see the impact of certain variables on supply chain decisions. The model and methodologies can also be generalized to biomass supply chain planning in other countries. More specific operational constraints can be added to the model.

While the current model considers uncertainty from demand and supply capacity, to make them more realistic, other factors that contain uncertainty need to be considered as well. One of the most important factors that affects biomass plant location is flood occurrence. Therefore, the model can be further extended to deal with flood occurrence in Vietnam. As the biomass supply chain tends to increase in scale and complexity, a possible extension would be to propose other heuristic algorithms such as Bender's decomposition and data mining with optimization, which can improve the solution quality and speed up the solving time.

Author Contributions: Conceptualization, N.N.; Data curation, D.N.D.; Funding acquisition, N.N.; Methodology, N.N., D.N.D.; Project administration, N.N.; Software, N.N., D.N.D.; Writing-original draft, D.N.D.; Writing-review and editing, N.N., D.N.D. 
Funding: This research was partly supported by the national budget fund in fiscal year 2018, Contract No. 26/2561.

Conflicts of Interest: The authors declare no conflict of interest.

\section{References}

1. Bjelić, I.B.; Rajaković, N. Simulation-based optimization of sustainable national energy systems. Energy 2015, 91, 1087-1098. [CrossRef]

2. Nikolopoulou, A.; Ierapetritou, M.G. Hybrid simulation based optimization approach for supply chain management. Comput. Chem. Eng. 2012, 47, 183-193. [CrossRef]

3. Cambero, C.; Sowlati, T.; Marinescu, M.; Röser, D. Strategic optimization of forest residues to bioenergy and biofuel supply chain. Int. J. Energy Res. 2015, 39, 439-452. [CrossRef]

4. Liu, W.Y.; Lin, C.C.; Yeh, T.L. Supply chain optimization of forest biomass electricity and bioethanol coproduction. Energy 2017, 139, 630-645. [CrossRef]

5. Jonker, J.G.G.; Junginger, H.M.; Verstegen, J.A.; Lin, T.; Rodríguez, L.F.; Ting, K.C.; van der Hilst, F. Supply chain optimization of sugarcane first generation and eucalyptus second generation ethanol production in Brazil. Appl. Energy 2016, 173, 494-510. [CrossRef]

6. Asian Development Bank. VIET NAM: Energy Sector Assessment, Strategy, and Road Map. Asian Development Bank. Available online: https:/www.adb.org/sites/default/files/institutional-document/178616/vie-energyroad-map.pdf (accessed on 7 May 2017).

7. Toan, P.K.; Bao, N.M.; Dieu, N.H. Energy supply, demand, and policy in Viet Nam, with future projections. Energy Policy 2011, 39, 6814-6826. [CrossRef]

8. Li, R.Y.M.; Li, H.C.Y. The challenge of sustainability in China's built environment: A comparison between urban and rural areas. Int. J. Sustain. Real Estate Constr. Econ. 2018, 1, 123-141.

9. Lind, T.; Hokkinen, J.; Jokiniemi, J.K.; Saarikoski, S.; Hillamo, R. Electrostatic precipitator collection efficiency and trace element emissions from co-combustion of biomass and recovered fuel in fluidized-bed combustion. Environ. Sci. Technol. 2003, 37, 2842-2846. [CrossRef]

10. Vega, F.; Alonso-Fariñas, B.; Benito Navarrete, B. Technologies for control of sulfur and nitrogen compounds and particulates in coal combustion and gasification. In New Trends in Coal Conversion; Suárez-Ruiz, I., Diez, M.A., Rubiera, F., Eds.; Wookhead Publishing: Cambridge, UK, 2019; pp. 141-173.

11. Yilmaz, S.; Selim, H. A review on the methods for biomass to energy conversion systems design. Renew. Sustain. Energy Rev. 2013, 25, 420-430. [CrossRef]

12. Salem, R.W.; Haouari, M. A simulation-optimisation approach for supply chain network design under supply and demand uncertainties. Int. J. Prod. Res. 2017, 55, 1845-1861. [CrossRef]

13. Ekşioğlu, S.D.; Acharya, A.; Leightley, L.E.; Arora, S. Analyzing the design and management of biomass-to-biorefinery supply chain. Comput. Ind. Eng. 2009, 57, 1342-1352. [CrossRef]

14. Kratica, J.; Dugošija, D.; Savić, A. A new mixed integer linear programming model for the multi level uncapacitated facility location problem. Appl. Math. Model. 2014, 38, 2118-2129. [CrossRef]

15. Dengiz, B.; İç, Y.T.; Belgin, O. A meta-model based simulation optimization using hybrid simulation-analytical modeling to increase the productivity in automotive industry. Math. Comput. Simul. 2016, 120, 120-128. [CrossRef]

16. Duc, D.N.; Nananukul, N. Supply chain model for renewable energy resource from biomass in Vietnam. In Proceedings of the 5th International Conference on Industrial Engineering and Applications, Singapore, 26-28 April 2018; pp. 520-525.

17. Duc, D.N.; Nananukul, N. A hybrid methodology for renewable energy supply chain management in Vietnam. In Proceedings of the 48th Conference on Computer and Industrial Engineering, Auckland, New Zealand, 2-5 December 2018; pp. 1-14.

18. Wu, B.; Sarker, B.R.; Paudel, K.P. Sustainable energy from biomass: Biomethane manufacturing plant location and distribution problem. Appl. Energy 2015, 158, 597-608. [CrossRef]

19. Gonela, V. Stochastic optimization of hybrid electricity supply chain considering carbon emission schemes. Sustain. Prod. Consum. 2018, 14, 136-151. [CrossRef]

20. Sarker, B.R.; Wu, B.; Paudel, K.P. Modeling and optimization of a supply chain of renewable biomass and biogas: Processing plant location. Appl. Energy 2019, 239, 343-355. [CrossRef] 
21. Papapostolou, C.; Kondili, E.; Kaldellis, J.K. Development and implementation of an optimization model for biofuels supply chain. Energy 2011, 36, 6019-6026. [CrossRef]

22. Wang, Y.; Ebadian, M.; Sokhansanj, S.; Webb, E.; Lau, A. Impact of the biorefinery size on the logistics of corn stover supply-A scenario analysis. Appl. Energy 2017, 198, 360-376. [CrossRef]

23. Sharma, B.; Clark, R.; Hilliard, M.R.; Webb, E. Simulation Modeling for Reliable Biomass Supply Chain Design Under Operational Disruptions. Front. Energy Res. 2018, 6. [CrossRef]

24. Vieira, A.A.; Dias, L.M.; Santos, M.Y.; Pereira, G.A.; Oliveira, J.A. Simulation of an automotive supply chain using big data. Comput. Ind. Eng. 2019, 137, 106033. [CrossRef]

25. Akhtari, S.; Sowlati, T.; Siller-Benitez, D.G.; Roeser, D. Impact of inventory management on demand fulfilment, cost and emission of forest-based biomass supply chains using simulation modelling. Biosyst. Eng. 2019, 178, 184-199. [CrossRef]

26. Chu, Y.; You, F.; Wassick, J.M.; Agarwal, A. Simulation-based optimization framework for multi-echelon inventory systems under uncertainty. Comput. Chem. Eng. 2015, 73, 1-16. [CrossRef]

27. Chávez, H.; Castillo-Villar, K.K.; Herrera, L.; Bustos, A. Simulation-based multi-objective model for supply chains with disruptions in transportation. Robot. Comput. Integr. Manuf. 2017, 43, 39-49. [CrossRef]

28. Ye, W.; You, F. A computationally efficient simulation-based optimization method with region-wise surrogate modeling for stochastic inventory management of supply chains with general network structures. Comput. Chem. Eng. 2016, 87, 16. [CrossRef]

29. Ge, H.; Nolan, J.; Gray, R.; Goetz, S.; Han, Y. Supply chain complexity and risk mitigation-A hybrid optimization-simulation model. Int. J. Prod. Econ. 2016, 179, 228-238. [CrossRef]

30. Tsai, S.C.; Chen, S.T. A simulation-based multi-objective optimization framework: A case study on inventory management. Omega 2017, 70, 148-159. [CrossRef]

31. Avci, M.G.; Selim, H. A multi-objective simulation-based optimization approach for inventory replenishment problem with premium freights in convergent supply chains. Omega 2018, 80, 153-165. [CrossRef]

32. Kelle, P.; Woosley, J.; Schneider, H. Pharmaceutical supply chain specifics and inventory solutions for a hospital case. Oper. Res. Health Care 2012, 1, 54-63. [CrossRef]

33. Tsai, S.C.; Zheng, Y.X. A simulation optimization approach for a two-echelon inventory system with service level constraints. Eur. J. Oper. Res. 2013, 229, 364-374. [CrossRef]

34. Fischer, J.H.; Pfeiffer, D.; Hellingrath, B.; Scavarda, L.F.; Martins, R.A. Robust parameter setting of supply chain flexibility measures using distributed evolutionary computing. Procedia CIRP 2014, 19, 75-80. [CrossRef]

35. Kaminsky, P.M.; Liu, S. A two-step gradient estimation approach for setting supply chain operating parameters. Comput. Oper. Res. 2018, 92, 98-110. [CrossRef]

36. Kush, Y.; Skrypin, V.; Galkin, A.; Dolia, K.; Tkachenko, I.; Davidich, N. Regularities of Change of The Supply Chain Operation Efficiency, Depending on The Parameters of The Transport Process. Transp. Res. Procedia 2018, 30, 216-225. [CrossRef]

(C) 2019 by the authors. Licensee MDPI, Basel, Switzerland. This article is an open access article distributed under the terms and conditions of the Creative Commons Attribution (CC BY) license (http://creativecommons.org/licenses/by/4.0/). 